\title{
Effects of flipped instruction on the performance and attitude of high school students in mathematics
}

\author{
Remalyn Q. Casem ${ }^{1 *}$ \\ 'Don Mariano Marcos Memorial State University, PHILIPPINES
}

Published: March 25, 2016

\begin{abstract}
This study aimed to determine the effects of flipped instruction on the performance and attitude of high school students in Mathematics. The study made use of the true experimental design, specifically the pretest-posttest control group design. There were two instruments used to gather data, the pretest-posttest which was subjected to validity and reliability tests and the Modified Fennema-Sherman Attitudes Scale. It was found out that the experimental and control groups were comparable in the pretest and posttest. Comparison on their gain scores revealed significant difference with performance of the experimental group higher than the control group. There was no significant difference on the level of attitude of the participants in the experimental group before and after the study in terms of confidence in learning mathematics, attitude toward success in mathematics, mathematics anxiety and perception of teacher's attitudes. A very weak positive relationship existed between performance and attitudes toward mathematics.
\end{abstract}

\begin{abstract}
Keywords
inverted classroom, flipped instruction, mathematics performance, attitude towards mathematics

Received: 5 Jan 2016

Revised: 22 Feb 2016

Accepted: 4 Mar 2016
\end{abstract}

DOI: $10.20897 /$ lectito. 201620

\section{BACKGROUND/ OBJECTIVES AND GOALS}

The main objective of teaching is learning. This is why teachers are continually trying out effective approaches that will work for particular subjects. A typical classroom allocates time in a way familiar to anyone: students gather during class sessions to hear lectures from a teacher and take down notes, and then students work on homework and projects outside of class. This traditional classroom setup is not best for learning. Students are expected to be inside the classroom with maximum teacher's supervision when they need the least help and they are faced with easier cognitive activities. The more difficult tasks given to students are usually done outside the classroom on their own without the help of the teacher or their peers. Inverting the setup of the classroom seems to be an improvement: students acquire fundamental concepts and basic learning competencies through readings, video lectures and other sources outside the classroom, and then put them to work on high-level cognitive tasks inside the classroom (Talbert 2012). In this way, students do challenging tasks inside the classroom where teacher's help is much needed and easily be extended to them. The inverted classroom promises conforms to the way students learn today in this digital world. It promises a more engaging and effective instruction process. In fact, students became engaged in the material more regularly than before inverting the classroom setup and had shown enthusiasm in classroom discussion (Gaughan 2014).

In a traditional classroom, instruction is primarily given inside the classroom in a 60-to-90-minute time allotment where students learn the basics of the lesson and are sent home with a great deal of similar tasks given inside the classroom but with increased level of difficulty. Conversely, in an inverted classroom, the 
setup is exactly opposite. Flipped instruction is an approach applied in an inverted classroom. Flipped is a specialized term for the general term blended (Margulieux et al. 2014). Flipped instruction employs interactive learning tasks inside the classroom, and direct individual instruction outside the classroom. In this approach, the content is delivered as homework through video tutorials, online interactive activities or reading assignments. Prior instruction is given outside the classroom through varied sources meticulously prepared or collated by the teacher to the students for them to learn the basics on their own, in lieu of letting the teacher lecturing in class. The classroom then becomes the place to work through problems, advance concepts, and to engage in collaborative learning. The 60-to-90-minute class time is used to further students' learning. Flipped instruction makes students get actively involved and cognitively awakened. It makes teachers easily query individual students, check out for misconceptions on some concepts, and clarify incorrect notions. With this approach, there is an individualize learning for all students, which will certainly increase their achievement and interest level. Students are learning with control of time, place and pace. Students learn best when they are in an environment that gives them the opportunity to feel competence, relatedness, and autonomy (Deci \& Ryan 2000).

Educators want to break the traditional lecture-oriented instructional model by focusing on student learning needs and capitalizing their potentials. Flipped instruction can enable teachers to shift from teacherdriven to student-centered learning. This shift unveils one characteristic in an outcomes-based education where students are responsible for their own learning and the teacher acting as guide-on-the-side. Flipped instruction also addresses the development of media and technology skill, a 21st century skill the K-to-12 curriculum promises to cultivate among basic education students.

Moreover, according to Peter Pappas, an international trainer on the improvement of the quality of teaching and learning, in a webinar he delivered in 2012 at his website peterpappas.com, there are two key factors driving the increased adoption of the flipped classroom model: poor learning outcomes and prevalence of online video. Based on his report, only $69 \%$ of students who start high school finish four years later, and an average of 7,200 students drop out of high school each day, totaling 1.3 million a year. One culprit to this alarming statistics is on the traditional model 'one-size-fits-all' of education teachers have been adopting. This model often results in limited concept engagement and severe consequences. Moreover, the availability of online video and increasing student access to technology has paved the way for flipped classroom models.

As an educator, the researcher never ceases to improve her teaching in order to ensure students' learning by trying out various ways that may seem to work for others and staying updated with current trends in education keeping in mind students' learning styles. It is with this reason that the researcher conceptualized this study.

This study aimed to determine the effects of flipped instruction on the performance and attitude of high school students in Mathematics IV of DMMMSU-MLUC, SY 2014-2015.

Specifically, this study sought answers to the following questions:

1. What is the level of performance of the experimental and control groups in the pretest and posttest in Mathematics IV?

1.1. Is there a significant difference on the level of performance of the two groups of participants in the pretest and posttest in Mathematics IV?

2. What is the level of attitude toward Mathematics IV of the participants in the experimental group before and after the study in terms of the following:

a. confidence in Mathematics;

b. attitude toward success in Mathematics;

c. anxiety toward Mathematics; and

d. perception of Mathematics teacher's attitudes?

2.1 Is there a significant difference on the level of attitude toward Mathematics IV of the participants in the experimental group before and after the study in terms of the four attitudinal domains?

3. Is there a significant relationship between the level of Mathematics performance and the level of attitude toward the subject of the experimental group?

\section{METHODS}

This study employed the true experimental research design particularly the pretest-posttest control group research design to obtain adequate control of sources of invalidity. Descriptive-correlational research design 
Table 1. Result of equivalency test

\begin{tabular}{cccc}
\hline & Mean & Variance & t-Stat \\
\hline Control Group & 87.58 & 13.17 & 0.0000 \\
Experimental Group & 87.58 & 13.54 & \\
* Significant at $\alpha=0.05$ & & &
\end{tabular}

was also utilized to determine the level of performance and attitudes of the participants toward mathematics, as well as the extent of relationship between the two variables.

Twenty four (24) fourth year high school students of DMMMSU-MLUC with Mathematics grades ranging from 82-95 were included in the study. There were twelve (12) randomly selected participants for each group. The researcher ensured equivalency of the two groups of participants by randomly selecting students for the control group with almost the same averages as that of their counterparts in the experimental group. To establish equivalency of the experimental and control groups more objectively, t-test was used to check differences on the means of their Mathematics grades. A $t$ statistic equal to 0 compared to a critical $t$ value 2.07 at 0.05 level of significance revealed that there is no significant difference between the two groups of participants (See Table 1). The two groups had almost the same variation in their grades.

Participants in the control group were taught using traditional instruction which made used of the lecture method, boardworks, drills and worksheets singly or in combination. Participants in the experimental group were exposed to flipped instruction with video lectures as homework and drills as classwork. The researcher made every effort to teach the traditional group to the best of her ability so as not to sway the findings of this study.

There were two instruments used in the study: the pretest-posttest on the selected topics in Mathematics IV and the Modified Fennema-Sherman Mathematics Attitude Scale. The pretest-posttest constructed by the researcher was used to gather data in order to determine the performance of the two groups of participants before and after the study. The Modified Fennema-Sherman Mathematics Attitudes Scale was used to gather data pertaining to the attitudinal influence of flipped instruction to the participants in the experimental group. It was a 48- item scale which consisted of four sub-scales, namely: Confidence in Learning Mathematics Subscale, Attitude Toward Success in Mathematics Subscale, Mathematics Anxiety Subscale and Teacher Perceptions Subscale. The Confidence in Learning Mathematics Subscale was intended to measure the confidence in one's ability to learn and to perform well on mathematical tasks. The Mathematics Anxiety Subscale was intended to measure feelings of anxiety, dread, nervousness, and associated bodily symptoms related to doing mathematics. The Attitude Toward Success in Mathematics Subscale aimed to measure students' beliefs about success in learning mathematics. The Teacher Perceptions Subscale was used to assess students' perceptions of how their teachers feel about them as students of mathematics. Each sub-scale consisted of 12 statements related to the learning of mathematics. Six were positively worded and six were negatively worded. Students responded to a statement by indicating the degree to which they agree or disagree with that statement.

The possible responses were "strongly agree", "agree", "undecided", "disagree", and "strongly disagree." The responses were interpreted as follows: SA (Strongly Agree) means the participant was in strong agreement with the attitude item; A (Agree) means the participant was in agreement with the attitude item; U (undecided) means that the participant had no clear-cut decision whether to agree or disagree with the attitude item; D (Disagree) means the participant was in disagreement with the attitude item; SD (Strongly Disagree) means the participant was in strong disagreement with the attitude item. Each response was given a value from 1 to 5 , accordingly. Positively-worded statements were scored based on the actual responses of the participants. On the other hand, negatively-worded statements were reversely scored.

The draft of the pretest/ posttest which originally consisted 35 items was reproduced and subjected for pilot testing by the researcher to 30 randomly selected fourth year high school students from Luna National High School, La Union, Philippines.

To establish internal consistency of the 35-item pretest-posttest, the Kuder-Richardson Formula 20 was used. The computed reliability coefficient of 0.82 indicates that the test was reliable. It satisfied the reliability coefficient requirement for a classroom exam which is at least 0.70 (Wells \& Wollack 2003). Though the test was highly reliable, two (2) items were discarded due to very low (too easy) and very high (too difficult) difficulty indices. Point biserial values of the items were computed to determine which ones were likely to be unreliable. A recommended point biserial value is at least 0.15 and items with point biserial values lower than 0.15 may need further examination or may be deleted (Varma n.d.).This is the basis on the deletion of eight 
(8) more items on the original pretest-posttest. The 35 -item pretest-postest was trimmed down to only 25 items.

The final pretest-posttest was comprised of 25 items. The coefficient of reliability of this test instrument was also computed. The final test was reliable with reliability coefficient of 0.84 which was an improvement from the original test.

To establish content validity of the pretest-posttest, five subject matter experts were asked to evaluate the instrument. The overall median of the valuators' judgments, 4 , clearly revealed that the 25 -item test was valid.

Data gathered were analyzed statistically by the researcher. Mean was used to determine the level of Mathematics performance of the two groups of participants in the pretest and posttest. The t-test was performed to find out if significant difference existed on the level of performance of the two groups of participants before and after the conduct of the study. Mean gain score and Cohen's d were used to determine the effect size of the use of flipped instruction on Mathematics performance of the participants.

Median was used to compute the level of attitude of the participants in the experimental group in terms of confidence in learning mathematics, attitude toward success in mathematics, mathematics anxiety and perception of teacher's attitudes. Wilcoxon's signed ranks test was used to determine if significant difference existed on the level of attitude of the participants in the experimental group before and after the conduct of the study. Cliff's delta was used to determine the effect size of the use of flipped instruction on participants' attitude toward Mathematics.

Spearman's rank order correlation was used to measure the strength of relationship between the level of performance and the level of attitude of the participants in the experimental group and to determine if significant relationship existed between the two variables.

SPSS and Microsoft Excel were used to facilitate the statistical computation of the data.

\section{RESULTS}

\section{Level of mathematics performance}

Table 2 shows the pretest mean scores of the experimental and control groups, 6.25 and 6.08 , respectively. This result indicates that the level of pretest performance of the two groups were both "fair". This is due to the fact that about 91 percent of the participants in each group got scores that are below 10, which means that almost all the participants in each group got unsatisfactory ("poor" and "fair") ratings. This result is expected because the topics included in the test were not yet discussed. The competencies were still about to be learned.

The experimental group had a higher pretest mean score compared to the control group but the performance of the former had much greater variation than that of the latter.

Table 2 further shows that the pretest mean scores of the two groups differ by 0.17 but their level of performance in the pretest did not differ significantly. This was revealed by the computed t value of -0.511 which is higher than the critical value of -2.074 . This is attested by the probability value of 0.614 which is higher than the 0.05 margin of error. This means that the experimental group is comparable to the control group in terms of entry characteristics. This implies that the control variable, third quarter Mathematics grade ranging from 82 to 95 , was effectively mapped and the random distribution of the participants in the experimental and control groups was of equal chance.

The overall posttest performance of the experimental and control groups were both "very satisfactory" as indicated by their mean scores of 19.33 and 16.75, respectively (See Table 3). The two groups had almost equal variation on their posttest performance. To check whether their posttest mean difference of 2.58 is large enough to support the rejection of the null hypothesis, t-test was performed. It was revealed that their

Table 2. Comparative pretest performance of the groups

\begin{tabular}{cccc}
\hline & Mean & Variance & t-Stat \\
\hline Control Group & 6.08 & 4.33 & \multirow{2}{*}{0.511} \\
Experimental Group & 6.25 & 7.15 & \\
\hline
\end{tabular}

* Significant at $\alpha=0.05$

Table 3. Comparative posttest performance of the groups

\begin{tabular}{cccc}
\hline & Mean & Variance & t-Stat \\
\hline Control Group & 16.75 & 10.39 & -1.97 \\
*xperimental Group & 19.33 & 10.24 &
\end{tabular}


posttest performance did not differ significantly as shown by the computed $t$ value of -1.97 which falls on the non-rejection region. This result signifies that there is no significant difference in the posttest performance of the experimental and control groups.

The considerable increase on the marks of the participants in the posttest as compared from that in the pretest can be primarily explained by the fact that the topics were already taught to them. But to have a deeper comparison between the two groups, the point of interest, therefore, is on how much they have improved. The researcher also measured the amount of growth in each group (gain score) and found that from pretest to posttest, the experimental group averaged $9.67 \%$ more growth than the traditional group. Table 4 shows that the experimental group had a mean gain score of 13.08 while the control group was 10.67. A t value of -2.12 , which is lower than the critical value of -2.074 , explains that their gain scores differ significantly. Though the two groups performed basically at the same level in the pretest and posttest, the significant difference on their gain scores suggests that those participants in the experimental group improved better than those in the control group. This implies that the use of flipped instruction had a positive effect on the mathematics performance of the participants in the experimental group. But as to what extent is the effect of flipped instruction on the mathematics performance can be explained by the effect size. The effect size based on the gain scores computed using Cohen's d was 0.9. This result can be interpreted as "large effect" based on Cohen's standard (Becker 2000). Thus, it can be said that flipped instruction had a large effect on the improvement of mathematics performance of the participants. This is because within the flipped model students were better able to prepare for the class sessions and had more opportunities to interact with the instructor and peers than during traditional lectures.

This finding is parallel with other researches conducted, which found similar results in other subject areas, including calculus, chemistry, physics, and engineering (Sahin et.al 2014, ALRowais 2014, Bell 2015, Chester et. al. 2011). Further, with regards to the effect of flipped instruction on students' performance, some studies showed that improvement on student learning and total comprehension took place in the flipped classroom. Ruddick (2012) reported that there were significant improvements on students' scores in the flipped classroom compared to student scores in the traditional classroom. Further, in a study at Virginia State University found that students in a flipped classroom environment scored $8.6 \%$ better in the class on average over the traditionally taught course (Talley \& Scherer 2013). These results clearly show that flipped instruction has a positive effect on students' performance.

\section{Attitude toward mathematics}

Before the study, the experimental group had its highest median rating in terms of perceptions of teacher's attitudes whereas its lowest mean rating was in terms of mathematics anxiety (See Table 5). This result shows that the students' anxiety towards Mathematics does not necessarily caused by teacher's disposition. It may be attributed by other factors such as unpleasant experiences related to the study of Mathematics. The overall attitude toward mathematics of the participants in the experimental group before they were exposed to flipped instruction was "highly favorable" as indicated by the median rating of 4 . It seems that the attitude of the participants toward Mathematics did not change after the study as shown by the overall median rating on the four attitudinal domains which was still 4. A number of participants exhibited the same responses for particular items before and after the study. This result may be explained, in part, by the time frame of the study. One cannot expect a sudden favorable change in attitude in a short period of time. However, it is

Table 4. Comparison on the gain scores of the two groups

\begin{tabular}{ccccc}
\hline & Mean & Variance & t-Stat & $\mathrm{d}$ \\
\hline Control Group & 10.67 & 7.51 & $-2.12^{*}$ & 0.9 \\
Experimental Group & 13.08 & 8.08 & & \\
\hline
\end{tabular}

* Significant at $\alpha=0.05$

Table 5. Attitude test result of the experimental group

\begin{tabular}{|c|c|c|c|c|}
\hline & \multicolumn{2}{|c|}{ Median } & \multirow{2}{*}{ W } & \multirow{2}{*}{$\mathrm{d}$} \\
\hline & Before & After & & \\
\hline Confidence in Mathematics & 3.50 & 3.75 & 6 & 0.33 \\
\hline Attitude toward success in Mathematics & 3.50 & 4.00 & 16 & 0.06 \\
\hline Anxiety toward Mathematics & 3.00 & 3.00 & 2 & 0.00 \\
\hline Perception of Mathematics teacher's attitudes & 4.00 & 4.00 & 15 & 0.02 \\
\hline Overall Attitude & 4.00 & 4.00 & 10 & 0.00 \\
\hline
\end{tabular}

* Significant at $\alpha=0.05$ 
interesting to note that students had somehow gained more confidence in learning Mathematics and had better attitude toward success in Mathematics after the study as indicated by the increase in their median ratings of these two domains after the study. This means that the participants in the experimental group benefited from the flipped instruction when it comes to boosting their confidence and developing more positive attitude toward success in Mathematics. Students in the flipped class were more confident after the study because they did not feel anxious of missing or not understanding the material (Ruddick 2012) because they could re-watch the videos over and over again the videos when they miss something (Brunsell \& Horejsi 2013) and could ask questions during class sessions with their instructor or peers. Students' responses showed that flipped instruction prepared them better and enabled them to feel more confident in learning mathematics. Again, this finding can be seen to stem from the fact that students in the flipped classroom model have more freedom and flexibility to choose their preparation methods for the class (Fulton 2012). In fact, flipping the class even helps in sparking and retaining student interest in mathematics as reported by the study of Love et al. (2014) on flipping the linear algebra classroom. Their study found that flipped instruction students in the flipped classroom enjoyed the classes more.

Wilcoxon's signed ranks test revealed that there is no significant difference on the attitude of the experimental group toward Mathematics before and after the study on the four attitudinal domains. Moreover, the effect size of the use flipped instruction on the attitude of the participants is almost negligible. This result suggests that flipped instruction had no significant effect on the overall attitude of students.

However, some of the findings from researches conducted thus far would indicate that flipped instruction has a positive effect on students' attitude. In a survey of more than 500 teachers, $80 \%$ of them reported that flipping the classroom improved students' attitude (Brunsell \& Horejsi 2013). The study of Moore and Chung (2015) among twenty-five high school students revealed that the perceptions and attitudes of the participants were generally positive in the flipped classroom environment and that the students were motivated to use the web-based instructional videos to prepare for their expected learning outcomes. Their study lasted for four months and employed varied data gathering procedures such as survey, interview and observation. Moreover, the study of ALRowais (2014) showed that there was a positive effect of flipped model of instruction on both the students' achievement and their attitudes towards studying higher education courses. Additionally, Chester et al. (2011) found that a flipped classroom improves student behavior. The present study would have had similar results probably if the experimentation lasted longer and the data were analyzed using both quantitative and qualitative methods.

\section{Mathematics performance versus attitude toward mathematics}

Table 6 shows the result of the correlation test between the level of Mathematics performance and attitude of the experimental group toward Mathematics. Using the rule of thumb, the coefficient of correlation of 0.028 (lower than the critical value 0.648 at $\alpha=0.05$ ) indicates that there is very small association between the level of Mathematics performance and attitude of the experimental group toward Mathematics and that the relationship is not significant at 0.05 margin of error. This means that there is no significant relationship between the level of performance and attitude towards mathematics of the participants in the experimental group. Having favorable attitude appears to have no significant effect on getting good marks.

On the other hand, several research findings show that relationship exists between math achievement and attitudes towards mathematics and even posit that good achievers develop more positive attitudes than lower achievers (Mata et.al 2012, Lipnevich et.al. 2011, Sanchez et. al. 2004, Singh et.al. 2010). Additionally, DePaolo and McLaren (2006) found out that attitude has an impact on performance. Their study found that relationship between negative attitudes and poor exam performance appears to be particularly strong. Further, a study (Schenkel 2009) found that positive attitude about mathematics does have a positive impact on a student's classroom performance.

Table 6. Result of correlation test

\begin{tabular}{lccc}
\hline & & Average & r \\
\hline & Performance & 19.33 & 0.028 \\
& Attitude & 4 & 0.028 \\
\hline * Significant at $\alpha=0.05$ & & &
\end{tabular}




\section{REFERENCES}

ALRowais, A., 2014. The impact of flipped learning on achievement and attitudes in higher education, International Journal for Cross-Disciplinary Subjects in Education (IJCDSE), 4(1). Retrieved from http://www.infonomicssociety.org/IJCDSE/TheImpactof FlippedLearningonAchievementandAttitudesIn20HigherEducation.pdf.

Becker, L. A., 2000. Effect size. Retrieved from http://www.bwgriffin.com/gsu/courses/ edur9131/content/EffectSizeBecker.pdf.

Bell, M. R., 2015. An investigation of the impact of a flipped classroom instructional approach on high school students' content knowledge and attitudes toward the learning environment. (Graduate Thesis, Brigham Young University). Retrieved from http:/ / scholarsarchive.byu.edu/cgi/viewcontent.cgi? article $=5443 \&$ context $=$ etd.

Brunsell, E. and Horejsi, M., 2013. Flipping your classroom in one "take". The Science Teacher. Retrieved from https://www.questia.com/library/journal/ 1G1-323260080/flipping-your- classroom-in-one-take.

Chester, A., Buntine, A., Hammond, K. and Atkinson, L., 2011. Podcasting in education: student attitudes, behaviour and self efficacy. Educational Technology \& Society, 14(2), pp.236-247. Retrieved from http://www.ifets.info/journals/14_2/20.pdf.

Deci, E. L. and Ryan, R. M., 2000. Intrinsic and extrinsic motivations: classic definitions and new directions. Contemporary Educational Psychology, 25(1), pp.54-67.

DePaolo, C. and McLaren, C. H., 2006. The relationship between attitudes and performance in business calculus, INFORMS Transactions on Education, 6(2). http://ite.pubs.informs.org/Vol6No2/DepaoloMclaren/.

DeVaney, T. A., 2012. Anxiety and attitude of graduate students in on-campus vs. online statistics courses. Journal of Statistics Education, 18(1). Retrieved from http://www.amstat.org/publications/jse/v18n1/devaney.pdf.

Finney, S. J. and Schraw, G., 2003. Self-efficacy beliefs in college statistics courses (Abstract). Contemporary Educational Psychology, 28(2), pp.161-186. $\quad$ Retrieved from http://www.sciencedirect.com/science/article/pii/S0361476X02000152.

Fulton, K., 2012. Upside down and inside out: flip your classroom to improve student learning. Learning \& Leading with Technology, 39(8), pp.12-17. Retrieved from http://files.eric. ed.gov/ fulltext/EJ982840.pdf.

Gaughan, J. E., 2014. The flipped classroom in world history. The History Teacher, 47(2), pp.221-244. Retrieved from http://www.societyforhistoryeducation.org/pdfs/ F14_Gaughan.pdf.

Kim, K. J. and Bonk, C. J., 2006. The future of online teaching and learning in higher education: The survey says... EDUCAUSE Quarterly, 29(4), pp.22-30. Retrieved from http://er.educause.edu/ /media/files/articledownloads/eqm0644.pdf

Lipnevich, A. A., MacCann, C., Krumm, S., Burrus, J. and Roberts, R. D., 2011. Mathematics attitudes and mathematics outcomes of US and Belarusian middle school students (Abstract). Journal of Educational Psychology, 103(1), pp.105118. Retrieved from http://eric.ed.gov/?id=EJ933605.

Love, B., Hodge, A., Grandgenett, N. and Swift, A. W., 2014. Student learning and perceptions in a flipped linear algebra course. International Journal of Mathematical Education in Science and Technology, 45(3), pp.317-324. Retrieved from http://www.tandfonline.com/doi/full/10.1080/0020739X.2013.822582.

Margulieux, L. E., Bujak, K. R., McCracken, W. M. and Majerich, D. M., 2014. Hybrid, blended, flipped, and inverted: defining terms in a two dimensional taxonomy. HICE Conference Proceedings. Retrieved from http://c21u.gatech.edu/sites/default/ files/HICEConferenceProceedings_1556_with citation [4].pdf.

Mata, M. D., Monteiro, V. and Peixoto, F., 2012. Attitudes towards mathematics: effects of individual, motivational, and social support factors. Child Development Research. Retrieved from http://www.hindawi.com/journals/cdr/2012/876028/.

McLeod, S. A., 2010. Simply Psychology; Zone of Proximal Development. Retrieved from http://www.simplypsychology.org/Zone-of-Proximal-Development.html.

Moore, C. and Chung, C., 2015. Students' attitudes, perceptions, and engagement within a flipped classroom model as related to learning mathematics. Journal of Studies in Education,5(3). Retrieved from http://www.macrothink. org/journal/index.php/jse/article/viewFile/8131/6686.

Ruddick, K. W., 2012. Improving chemical education from high school to college using a more hands-on approach. (Doctoral Dissertation, University of Memphis). Retrieved from http://gradworks.umi.com/35/29/3529991.html.

Sahin, A., Cavlazoglu, B. and Zeytuncu, Y. E., 2015. Flipping a college Calculus course: a case study. Educational Technology \& Society, 18(3), pp.142-152. Retrieved from http://www.ifets.info/journals/18_3/11.pdf.

Sanchez, K., Zimmerman, L. and Ye, R., 2004. Secondary students' attitudes toward mathematics. Academic Exchange Quarterly. Retrieved from https://www.questia.com/library/journal/1G1-121714089/secondary-studentsattitudes-toward-mathematics.

Schenkel, B., 2009. The impact of an attitude toward Mathematics on Mathematics. (Graduate Thesis, Marietta College). Retrieved from https://etd.ohiolink.edu/rws_etd/ document/get/marietta1241710279/inline.

Singh, K., Granville, M., and Dika, S., 2010. Mathematics and science achievement: effects of motivation, interest, and academic engagement. Journal of Educational Research. Retrieved from http://www.tandfonline.com/doi/abs/ $10.1080 / 00220670209596607$. 
Talbert, R., 2012. Inverted classroom. Colleagues, 9(1), Retrieved from http://scholarworks.gvsu.edu/colleagues/vol9/iss1/7.

Talley, C. P. and Scherer, S., 2013. The enhanced flipped classroom: increasing academic performance with studentrecorded lectures and practice testing in a "flipped" STEM course. Journal of Negro Education, 82(3), pp.339-347.

Varma, S., 2006. Preliminary item statistics using point-biserial correlation and p-values. Educational Data Systems Publications, Retrieved from: http://www.eddata.com/ resources/publications/EDS_Point_Biserial.pdf.

Wells, C. S. and Wollack, J. A., 2003. An Instructor's Guide to Understanding Test Reliability, Retrieved from: http:// testing.wisc.edu/Reliability.pdf. 